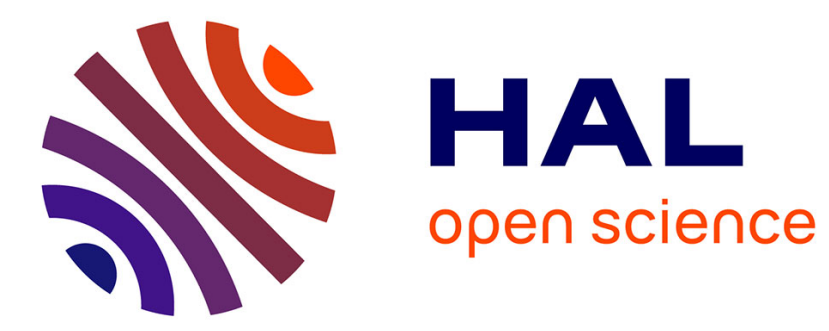

\title{
Solid Phase Synthesis of Helically Folded Aromatic Oligoamides
}

Simon J Dawson, Xiaobo Hu, Stijn Claerhout, Ivan Huc

\section{To cite this version:}

Simon J Dawson, Xiaobo Hu, Stijn Claerhout, Ivan Huc. Solid Phase Synthesis of Helically Folded Aromatic Oligoamides. Methods in Enzymology, Volume 580 - Peptide, Protein and Enzyme Design, pp.279 - 301, 2016, 10.1016/bs.mie.2016.05.011 . hal-01509567

\section{HAL Id: hal-01509567 \\ https://hal.science/hal-01509567}

Submitted on 18 Apr 2017

HAL is a multi-disciplinary open access archive for the deposit and dissemination of scientific research documents, whether they are published or not. The documents may come from teaching and research institutions in France or abroad, or from public or private research centers.
L'archive ouverte pluridisciplinaire HAL, est destinée au dépôt et à la diffusion de documents scientifiques de niveau recherche, publiés ou non, émanant des établissements d'enseignement et de recherche français ou étrangers, des laboratoires publics ou privés. 


\section{Solid phase synthesis of helically folded aromatic oligoamides}

Simon J. Dawson, ${ }^{\mathrm{a}, \mathrm{b}}$ Xiaobo Hu, ${ }^{\mathrm{a}, \mathrm{b}}$ Stijn Claerhout, ${ }^{\mathrm{a}, \mathrm{b}}$ and Ivan Huc ${ }^{\mathrm{a}, \mathrm{b}^{*}}$

${ }^{a}$ Université de Bordeaux, CBMN (UMR5248), Institut Européen de Chimie et Biologie, 2 Rue Escarpit, 33600 Pessac, France

${ }^{\mathrm{b}}$ CNRS, CBMN (UMR5248), Institut Européen de Chimie et Biologie, 2 Rue Escarpit, 33600, Pessac, France

*i.huc@iecb.u-bordeaux.fr

\section{Keywords}

Solid-phase synthesis; aromatic amino acids; foldamers; helical structures; microwaves; acid chlorides

\section{Abstract}

Aromatic amide foldamers constitute a growing class of oligomers that adopt remarkably stable folded conformations. The folded structures possess largely predictable shapes and open the way towards the design of synthetic mimics of proteins. Important examples of aromatic amide foldamers include oligomers of 7- or 8-amino-2-quinoline carboxylic acid that have been shown to exist predominantly as well-defined helices, including when they are combine with $\alpha$ amino acids to which they may impose their folding behavior. To rapidly iterate their synthesis, solid phase synthesis protocols have been developed and optimized for overcoming synthetic difficulties inherent to these backbones such as low nucleophilicity of amine groups on electron poor aromatic rings and a strong propensity of even short sequences to fold on the solid phase during synthesis. For example, acid chloride activation and the use of microwaves are required to bring coupling at aromatic amines to completion. Here, we report detailed solid phase synthesis protocols for the rapid production of: 1) oligomers of 8-amino-2-quinolinecarboxylic acid;2) 
oligomers containing 7-amino-8-fluoro-2-quinolinecarboxylic acid; 3) heteromeric oligomers of 8-amino-2-quinolinecarboxylic acid and $\alpha$-amino acids. Solid phase synthesis brings the advantage to quickly produce sequences having varied main chain or side chain components without having to purify multiple intermediates as in solution phase synthesis. With these protocols, an octamer could easily be synthesized and purified within one to two weeks from Fmoc protected amino acid monomer precursors.

\section{Introduction}

Foldamers, i.e. artificial folded molecular architectures, are the object of very active research investigations (Guichard \& Huc, 2011). While inspired by the folding behavior seen in natural biopolymers, they possess a fundamental difference, in that they are comprised of either nonnatural building blocks, or natural building blocks arranged in a non-natural sequence. Foldamers closely ressembling their natural counterpart have been termed 'biotic' and include peptide nucleic acids (Nielsen, Egholm, Berg \& Buchardt, 1991),peptoids (Simon, Kania, Zuckermann, Huebner, Jewell, Banville et al, 1992), $\beta$-peptides (Appella, Christianson, Karle, Powell \&

Gellman, 1996; Seebach, Overhand, Kühnle, Martinoni, Oberer, Hommel et al, 1996), $\gamma$ peptides, and $\delta$-peptides. They also include peptide sequences where amides have been replaced by urea, hydrazide, or hydroxyamide linkages (Semetey, Rognan, Hemmerlin, Graff, Briand, Marraud et al, 2002; Salaun, Potel, Roisnel, Gall \& Le Grel, 2005; Li \& Yang, 2006). In contrast, 'abiotic' foldamers consist of entirely unnatural building blocks, giving rise to backbones and folding modes which are inaccessible to natural motifs. These architectures may have unique physical properties, or may be capable of interacting with biomolecules in unforeseen and interesting ways. Many of these sequences are aromatic rich, examples including oligophenylene-ethynylenes (Nelson, Saven, Moore \& Wolynes, 1997), alternating aromatic electron 
donors and acceptors (Lokey \& Iverson, 1995), aryl-oligomers (often based on aza-heterocycles: pyridines, pyrimidines, pyridazines, etc. (Bassani, Lehn, Baum \& Fenske, 1997)), aromatic tertiary amide, imide, or urea oligomers, and aromatic oligoamides. (Hamuro, Geib \& Hamilton, 1996; Berl, Huc, Khoury, Krische \& Lehn, 2000; Zhu, Parra, Zeng, Skrzypczak-Jankun, Zeng \& Gong, 2000; Jiang, Léger \& Huc, 2003; Huc, 2004). Oligoamide foldamers are particularly attractive, since the amide linkage offers a high level of synthetic feasibility; indeed, this is the motif which has been selected by nature.

a)

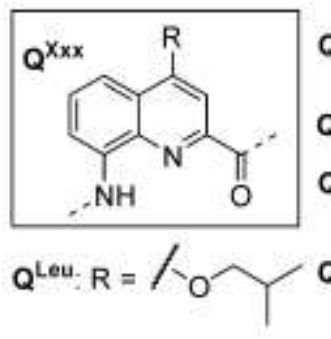

b)

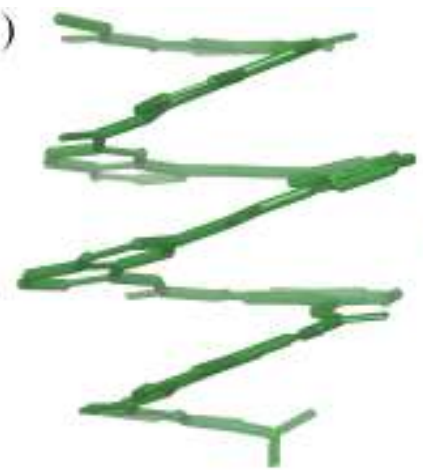

c)

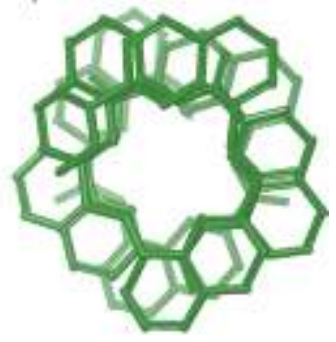

Figure 1: (a) structure of quinoline-based aromatic oligoamide foldamers with examples of available monomer side-chains. Side (b) and top (c) views of the crystal structures of $\mathrm{O}_{2} \mathrm{~N}$ $\left(\mathrm{Q}^{\mathrm{Leu}}{ }_{8}\right.$-OMe. Side chains and hydrogen atoms are omitted for clarity. Aromatic oligoamide foldamers consisting of 8-amino-2-quinolinecarboxylic acid (Figure 1) form single helical architectures made up of 2.5 monomer units per turn, with a pitch of $3.4 \AA$ that corresponds to the thickness of one aromatic ring (Figure 1b, 1c) (Jiang et al, 2003; Jiang, Léger, Dolain, Guionneau \& Huc, 2003; Dolain, Grélard, Laguerre, Jiang, Maurizot \& Huc, 2005). They feature key properties which make them ideal candidates for the recognition of sizeable surface areas of biomolecules: they are medium sized $(0.5-5.0 \mathrm{kDa})$, resistant to proteolytic degradation, and conformationally stable in a wide range of solvents and in particular in water, even at high temperatures (Qi, Maurizot, Noguchi, Charoenraks, Kauffmann, Takafuji 
et al, 2012; Gillies, Deiss, Staedel, Schmitter \& Huc, 2007). Indeed, to date no conditions have been found under which they do not adopt a helically folded conformation. Another advantage is that their helical shape is extremely predictable, and since monomer side-chains may be positioned away from the backbone amide motifs, folding is essentially independent of R-group functionality. This allows the display of arrays of side-chains to be tuned in order to optimize interactions with a specific biomolecule, affording foldamers with cell-penetrating properties (Gillies et al, 2007; Iriondo-Alberdi, Laxmi-Reddy, Bouguerne, Staedel \& Huc, 2010), high affinity for G-quadruplex DNA (Delaurière, Dong, Laxmi-Reddy, Godde, Toulmé \& Huc, 2012; Müller, Laxmi-Reddy, Jena, Baptiste, Dong, Godde et al 2014), or the potential to interact with protein surfaces. (Buratto, Colombo, Stupfel, Dawson, Dolain, Langlois d'Estaintot et al 2014). This high stability of helix shape also brings benefits in terms of synthetic availability. Once a trimer has been reached, addition of further monomer units only results in elongation of the helix under identical conditions regardless of helix length. This is in contrast to biopolymers such as peptides, where each synthetic intermediate may have a different conformation, potentially affecting reactivity in subsequent steps (e.g. by aggregation).

A logical extension from homogenous backbones (i.e. those consisting of exclusively one monomer type) is to combine a variety of different monomer types to produce a hybrid sequence. This concept highlights one of the advantages of synthetic foldamers, in that specific monomers can be included at any desired point to globally or locally direct sequence architecture in a predictable manner, and thus potentially access unsuspected areas of structural and functional space. For quinoline-based oligoamide foldamers, considerable inroads have been made into understanding the effect on helical structure when a diverse array of aromatic building blocks are included (Figure 2). Monomers such as those based on fluoroquinoline (' $\mathrm{Q}_{\mathrm{F}}$ ', 1) or anthracene 
$(' A$ ', 2) can be included to code for a wider helix diameter, which, combined in the centre of a quinoline sequence, can lead to the formation of a capsule shape. An example would be $\mathrm{Q}_{3}\left(\mathrm{Q}_{\mathrm{F}}\right)_{3} \mathrm{~A}\left(\mathrm{Q}_{\mathrm{F}}\right)_{3} \mathrm{Q}_{3}$. Through iterative design, cavity size and functionality can be reliably tuned to encapsulate a specific host, examples ranging from simple short-chain alkanes, to monosaccharides (Garric, Léger \& Huc, 2005; Bao, Kauffmann, Gan, Srinivas, Jiang \& Huc, 2008; Singleton, Pirotte, Kauffmann, Ferrand \& Huc, 2014; Chandramouli, Ferrand, Lautrette, Kauffmann, Mackereth, Laguerre et al, 2015). Short Q 3 quinoline sequences at each terminus of the capsule function as a type of 'cap' effectively insulating the cavity from the exterior. (Ferrand, Chandramouli, Kendhale, Aube, Kauffmann, Grélard et al, 2012) If these quinoline caps are removed, the wider diameter of, for example, a homomeric fluoroquinoline sequence results in hybridization into double (Figure 2b, 2c) and even quadruple helices (Gan, Bao, Kauffmann, Grélard, Xiang, Liu et al 2008). This behavior has even been shown to occur in aqueous conditions, representing one of the very few examples of water-soluble synthetic double helices reported in current literature (Shang, Gan, Dawson, Rosu, Jiang, Ferrand, et al, 2014).

a)
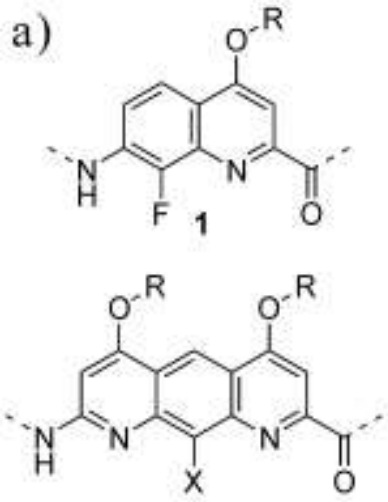

2

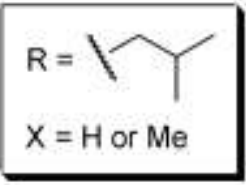

b)

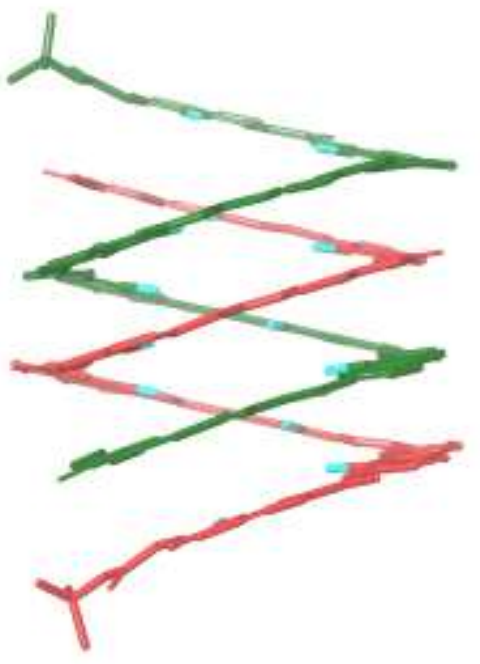

c)

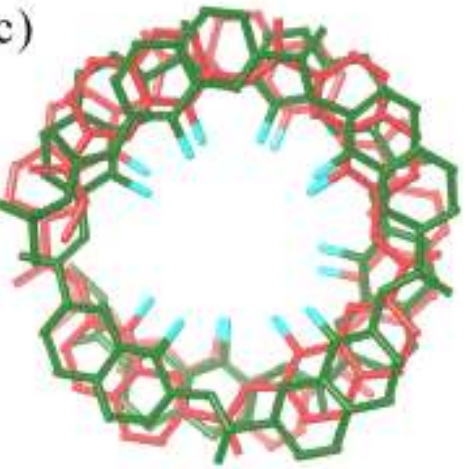


Figure 2: (a) Fluoroquinoline (1) and anthracene (2)-based monomers. Side (b) and top (c) views of the crystal structure of double helical $\left(\mathrm{Boc}-\left(\mathrm{Q}_{\mathrm{F}}{ }^{\mathrm{Leu}}\right)_{8}-\mathrm{OMe}\right)_{2}$. The backbone of each strand is colored in green or red. Fluorine atoms are colored blue. Side chains and hydrogen atoms are omitted for clarity.

Recent work in the Huc group has also focused on the inclusion of aliphatic units into aromatic oligoamide foldamer sequences, in particular, $\alpha$-amino acids. This is a natural progression from exclusively abiotic peptidomimetics, in that the exact functional groups which mediate biomolecule recognition (i.e. $\alpha$-amino acid side-chains) are included. This is also brings synthetic benefits, since a vast range of orthogonally protected $\alpha$-amino acids are commercially available, avoiding the need for (a perhaps laborious) bespoke monomer synthesis.

In the foldamer world, a single amino acid may for example be added at the extremity of an $\alpha$ helix mimetic (Barnard, Long, Martin, Miles, Edwards, Tomlinson et al, 2015). When multiple $\alpha$-amino acids are incorporated in an abiotic sequence to form a hybrid scaffold, the completely different folding principles of biotic and abiotic units may offer access to secondary structures distinct from those of biopolymers or synthetic homo-oligomers (Nair, Vijayadas, Roy \& Sanjayan, 2014). In other cases, the folding of abiotic units may be so effective that it forces $\alpha$ amino acids to adopt conformations distinct from those found in peptides. We recently reported examples of this kind using helically folded quinoline oligoamides. Sequences combining $\alpha-$ amino acid $(\mathbf{X})$ and quinoline $(\mathbf{Q})$ units together in an $\mathbf{X} \mathbf{Q}_{2}$ trimer repeat motif (Figure 3) were found to adopt a single well-defined canonical aromatic helical conformation in both organic and aqueous conditions (Kudo, Maurizot, Kauffmann, Tanatani \& Huc, 2013; Hu, Dawson, Kudo, Nagaoka, Tanatani \& Huc, 2016). In contrast, hybrids based on an XQ dimer repeat motif were 
found to adopt a partially folded zig-zag tape conformation with local conformational variability precluding long range order. This behavior was also evident in protic solvents, where the increased solvent-accessibility of the hydrophobic aromatic surfaces appeared to drive nonspecific aggregation at lower temperatures (Hu et al, 2016; Kudo, Maurizot, Masu, Tanatani, \& Huc, 2014) These types of hybrid foldamer sequences offer access to currently untapped areas of chemical space and may provide promising candidates for the recognition of 'difficult' biological targets such as protein-protein interactions.

a)

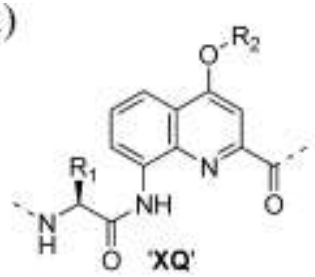

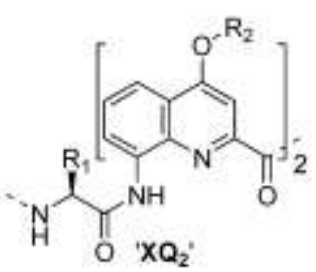

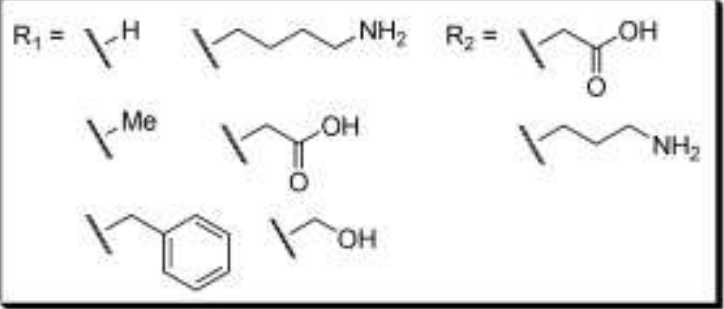

b)

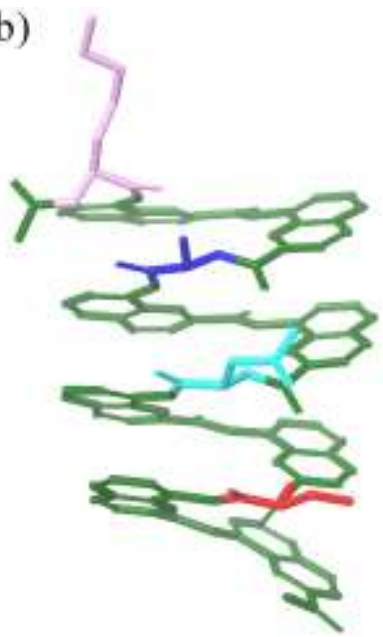

c)

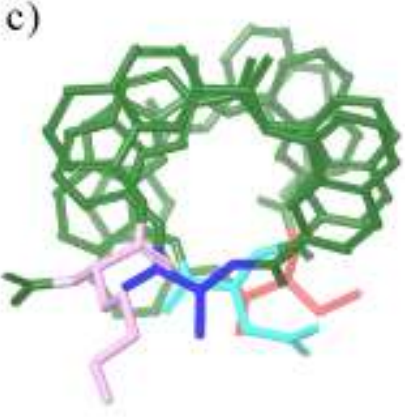

Figure 3: (a) $\mathbf{X Q}$ and $\mathbf{X} \mathbf{Q}_{2}$ motifs with $\alpha$-amino acids currently validated for incorporation. Side (b) and top (c) views of NMR structure of $\mathrm{Ac}-\mathrm{K}\left(\mathrm{Q}^{\mathrm{Orn}}\right)_{2} \mathrm{~A}\left(\mathrm{Q}^{\mathrm{Orn}}\right)_{2} \mathrm{D}\left(\mathrm{Q}^{\mathrm{Orn}}\right)_{2} \mathrm{~S}\left(\mathrm{Q}^{\mathrm{Orn}}\right)_{2}-\mathrm{OH}(\mathrm{Hu}$ et al, 2016). The aromatic backbone is colored in green and the $\alpha$-amino acid residues are in pink (Lys), blue (Ala), light blue (Asp) and red (Ser). Aromatic side-chains and hydrogen atoms are omitted for clarity.

With foldamers becoming increasingly complex, organic chemists require synthetic methodologies capable of meeting the requirements of their designs. The production of oligomers by solid phase synthesis (SPS) is particularly attractive in that it offers a method for rapidly generating sequence analogues where any monomer unit can be substituted for another, 
without the laborious re-synthesis of intermediates required by a more convergent solution phase approach. In addition, the pseudo-dilution effect of solid supported synthesis reduces intermolecular reactions between individual oligomer chains, and this 'site-site isolation' phenomenon (Shi, Wang \& Yan, 2007) can help minimize reactivity issues which might occur otherwise in solution due to aggregation, or hybridization behavior (e.g. as seen in the synthesis of fluoroquinoline double helical foldamers). While solid phase peptide synthesis methods are now widely standardized, the use of an SPS strategy for the production of aromatic foldamers based on 8-amino-2-quinolinecarboxylic acid is not without its challenges. The aromatic amine is a relatively poor nucleophile and thus coupling requires activation of monomers as acid chlorides and microwave assistance in order to be both rapid and essentially quantitative. Over the last number of years we have reported the SPS of increasingly elaborate oligomers, from homomeric quinoline sequences (Baptiste, Douat-Casassus, Laxmi-Reddy, Godde \& Huc, 2010) to heteromeric sequences containing fluoroquinoline monomers and $\alpha$-amino acids (Shang et al. 2014, Hu et al. 2016). We are now in a position to report here optimized protocols for the microwave-assisted SPS of these foldamers, including variations and improvements from previously published work. These protocols are specific to the requirements of these classes of oligomers, and are to be compared to solid phase synthesis methods developed for other aromatic amide oligomers (Wurtz, Turner, Baird \& Dervan, 2011; Puckett, Green \& Dervan, 2012; König, Abbel, Schollmeyer \& Kilbinger, 2006; Murphy, Prabhakaran, Azzarito, Plante, Hardie, Kilner et al. 2013)

\section{Materials}

\section{Reagents}


Acetyl chloride, acetic anhydride, $\mathrm{CaH}_{2}, \mathrm{CBr}_{4}, 1$-chloro-N,N,2-trimethyl-1-propenylamine ('Ghosez reagent'), CsI, 1-methyl-2-(4'-nitrophenyl)-imidazo[1,2-a]pyrimidinium perchlorate (DESC), dimethylformamide (DMF), dichloromethane, N,N-diisopropylethylamine (DIEA), isopropanol, Fmoc $\alpha$-amino acids, quinoline and fluoroquinoline monomers, methanol, nitrogen gas, piperidine, Sieber amide resin ('low loading' $~ 0.6-0.7 \mathrm{mmol} . \mathrm{g}^{-1}$ ), tetrahydrofuran (THF), trichloroacetonitrile (TCAN), trifluoroacetic acid, triisopropylsilane, triphenylphosphine, 2,4,6collidine, Wang resin ('low loading' $0.3-0.4$ mmol.g ${ }^{-1}$ ), water.

\section{Equipment}

Balloons, CEM Discover SPS microwave oven equipped with an infrared optical fiber optical fiber probe internal to the reaction mixture linked to an IR detector for temperature control, CEM SPS vacuum station with membrane vacuum pump (Vacuubrand model ME1), CEM SPS reactor vessel (25 mL, polypropylene) with end cap, vial heating block, micropipettes (Gilson, 20 and $100 \mu \mathrm{L}$ ), high vacuum pump (Vacuubrand model RC6) with glass vacuum manifold and cold finger, microsyringe (Hamilton, $100 \mu \mathrm{L}$ ), needles (disposable, $2.5 \mathrm{~cm}$ and $10 \mathrm{~cm}$ ), Pasteur pipettes, plastic syringes (disposable, 2,5 , and $10 \mathrm{~mL})$, round bottomed flasks $(10 \mathrm{~mL})$ with corresponding rubber septa, sample vials (approx $1-2 \mathrm{~mL}$ ), sintered glass filter funnel (approx 2 $\mathrm{mL}$, porosity grade 3), squeeze solvent wash bottles, stoppered vacuum adapters, rotary evaporator (Büchi, model R-3000) with vacuum pump (Büchi, model V-500) and vacuum controller (Büchi, model V-800).

\section{Reagent setup}

Resins: 'low-loading' resins are to be preferred, in order to avoid potential steric crowding when synthesizing longer oligoamide sequences. 
Dichloromethane: dry dichloromethane is obtained by filtration through activated alumina using a dedicated purification system (MBRAUN SPS-800) and should be used immediately. THF: dry THF is obtained by filtration through activated alumina using a dedicated purification system (MBRAUN SPS-800 and should be used immediately.

$\mathrm{N}, \mathrm{N}$-diisopropylethylamine: should be freshly distilled over $\mathrm{CaH}_{2}$ to remove traces of water and used immediately.

20\% v/v piperidine in DMF: solution should be freshly prepared.

0.1 M DESC in anhydrous DMF: solution should be freshly prepared.

Where not stated as anhydrous, all solvents used for rinsing the resin and reaction vessel can be delivered using plastic squeeze bottles.

The synthesis of various Fmoc protected 8-amino-2-quinolinecarboxylic acid and 7-amino-8fluoro-2-quinolinecarboxylic acid has been reported before (Baptiste et al. 2010, Buratto et al. 2014, Shang et al. 2014)

\section{Equipment setup}

Dry syringes and needles: Plastic syringes and needles directly used from the packaging are considered dry. When they are reused, they should be cleaned with acetone and dried under vacuum (at least for $1 \mathrm{~h}$ ).

Microwave: As of publication, these protocols have not been validated on microwave systems other than the CEM Discover. Follow manufacturer's instructions for setup of microwave cavity and vacuum station for SPS. The microwave should be run in 'open vessel' mode, with temperature control via an internal fibre optic probe. A standard temperature program should be used, with a 5 min ramp time and medium stirring speed. Hold times vary (see specific protocol).

\section{Synthetic protocols}




\section{8-Amino-2-quinolinecarboxylic acid-based oligoamides}

Notes: We show here as an example the synthesis of a water-soluble octameric quinoline oligoamide (Figure 4) on a $19 \mu \mathrm{mol}$ scale. In our experience, this protocol can be reliably scaled to approx $80 \mu \mathrm{mol}$ with no decrease in efficiency. We have successfully synthesized oligomers up to 24 units in length with these protocols. Protocols $3-6$ and 8 have also been validated using low-loading Sieber amide resin.

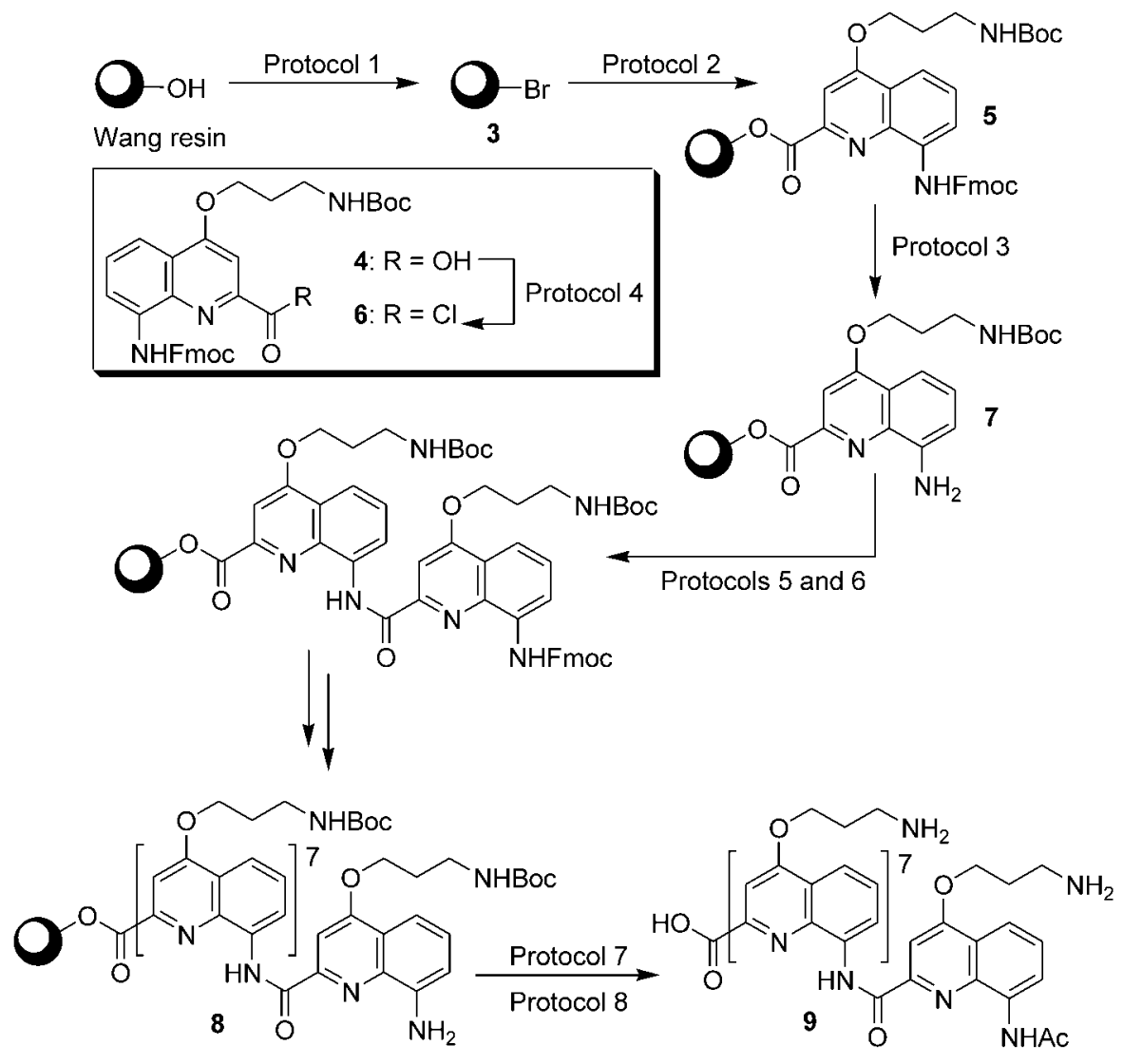

Figure 4: Summary of SPS protocols exemplified by synthesis of acetylated $Q^{\text {Orn }}$ octamer 9.

Protocol 1: Bromination of low-loading Wang resin 
Note: method based on the procedure of Morales and co-workers (Morales, Corbett \& DeGrado, 1998) where it is reported at larger scales. We exemplify here the procedure on a $76 \mu$ mol scale, which is routinely carried out in our laboratory.

Time required: $17 \mathrm{~h}$

1) Prepare a clean, dry $10 \mathrm{~mL}$ round bottomed flask equipped with small magnetic stirring bar, septum and nitrogen balloon.

2) Add Wang resin $\left(200 \mathrm{mg}, 76 \mu \mathrm{mol}\right.$ for $0.38 \mathrm{mmol} . \mathrm{g}^{-1}$ loading $)$ to the reaction flask, followed by $2 \mathrm{~mL}$ anhydrous DMF via dry syringe through the septum. Ensure all resin is rinsed from the sides of the flask, then flush with $\mathrm{N}_{2}$. Note that success of this reaction is highly dependent on the quality of the anhydrous DMF.

3) Leave resin to swell for $1 \mathrm{~h}$ under $\mathrm{N}_{2}$ atmosphere.

4) Remove the septum. While stirring the resin, add $\mathrm{PPh}_{3}$ (99.7 mg, $0.38 \mathrm{mmol}, 5$ equiv.) and $\mathrm{CBr}_{4}$ (126.1 $\mathrm{mg}, 0.38 \mathrm{mmol}, 5$ equiv.) rapidly in that order. Then equip with the septum and nitrogen balloon. Note that flask should warm noticeably, and the solution should develop a lasting yellow-orange coloration.

5) Stir for $15 \mathrm{~h}$ under $\mathrm{N}_{2}$ atmosphere.

6) Collect the resin by filtration and wash sequentially with anhydrous DMF ( $5 \mathrm{~mL})$, anhydrous $\mathrm{CH}_{2} \mathrm{Cl}_{2}(5 \mathrm{~mL})$ and isopropanol $(5 \mathrm{~mL})$. Repeat the washing cycle three times in total.

7) Dry the resin under vacuum in the desiccator.

\section{Protocol 2: Loading of Wang-bromide resin}

Time required: $1.5 \mathrm{~h}$ 
1) Prepare a clean, dry $10 \mathrm{~mL}$ round bottomed flask and equip with septum and nitrogen balloon.

2) Add Wang-bromide resin $\left(3,50 \mathrm{mg}, 19 \mu \mathrm{mol}\right.$ for $0.38 \mathrm{mmol}^{-1}{ }^{-1}$ loading $)$ to the flask, followed by approximately $1 \mathrm{~mL}$ of anhydrous DMF via dry syringe through the septum. Ensure all resin is rinsed from the sides of the flask, then flush with $\mathrm{N}_{2}$.

3) Leave resin to swell for $1 \mathrm{~h}$ under $\mathrm{N}_{2}$ atmosphere.

4) Equip a $25 \mathrm{~mL}$ polypropylene SPS microwave reaction vessel with the appropriate size magnetic stirring bar.

5) Transfer the swollen resin to the microwave reaction vessel as a slurry in anhydrous DMF. Rinse the round bottomed flask with small quantities of anhydrous DMF to allow transfer of residual resin. Remove residual anhydrous DMF from the reaction vessel using the vacuum station.

6) Remove reaction vessel from the vacuum station and fit end cap to avoid leakage.

7) To the reaction vessel, add $0.45 \mathrm{~mL}$ anhydrous $\mathrm{DMF}$, followed by Fmoc- $\mathrm{Q}^{\text {Orn-Boc-OH }}(\mathbf{4}$, $33.2 \mathrm{mg}, 0.057 \mathrm{mmol}, 3$ equiv.) and CsI (14.8 mg, $0.057 \mathrm{mmol}, 3$ equiv.). Add DIEA (9.9 $\mu \mathrm{L}, 0.057 \mathrm{mmol}, 3$ equiv.) using a micropipette.

8) Rinse the inside surface of the reaction vessel with a further $0.45 \mathrm{~mL}$ anhydrous DMF, to ensure all reagents are at the resin bed.

9) Insert optical fibre probe into the reactor vessel ensuring the tip is immersed in the reaction mixture and then place the vessel into the microwave cavity with the appropriate insert. Treat with microwaves: $50 \mathrm{~W}$, ramp to $50^{\circ} \mathrm{C}$, with a 5 min hold time.

10) Remove reaction vessel from microwave cavity, remove end cap and remove reagent solution on vacuum station. Rinse the inside surfaces of the reaction vessel with 
anhydrous DMF $(5 \mathrm{~mL})$ to remove reagents and ensure all displaced resin is moved down to the resin bed. Remove DMF on vacuum station and fit end cap to the vessel.

11) Repeat steps 7) to 9).

12) Remove reaction vessel from microwave cavity, remove fibre optic probe and end cap, then remove reagent solution using the vacuum station. Using DMF thoroughly rinse the inside surfaces of the reaction vessel (approx $10 \mathrm{~mL}$ DMF) and the resin itself (approx 10 $\mathrm{mL}$ DMF) to ensure all reagents have been removed.

13) Loading efficiency can be calculated using the same UV spectroscopic methods (based on liberated dibenzofulvene adducts from Fmoc deprotection) reported widely in the literature for solid phase peptide synthesis (White \& Chan, 2000).

\section{Protocol 3: Fmoc deprotection}

Time required: allow $40 \mathrm{~min}$.

1) To the loaded resin 5 in reaction vessel, add approximately $2-3 \mathrm{~mL}$ of a $20 \% \mathrm{v} / \mathrm{v}$ solution of piperidine in DMF. Stir at medium speed at room temperature for 10 min (can be carried out on a normal stirring plate if desired).

2) Remove end cap from reaction vessel and remove reagent solution on vacuum station. Rinse the inside surfaces of the reaction vessel with anhydrous DMF $(5 \mathrm{~mL})$ to remove reagents and ensure all displaced resin is moved down to the resin bed. Remove DMF on vacuum station and fit end cap to the vessel.

3) Repeat steps 1) and 2) twice more.

4) Using DMF thoroughly rinse the inside surfaces of the reaction vessel (approx $10 \mathrm{~mL}$ DMF) and the resin itself (approx $10 \mathrm{~mL}$ DMF) to ensure all reagents have been removed. 
Protocol 4: Conversion of N-Fmoc quinoline carboxylic acid monomer 4 to the corresponding acid chloride, $\mathbf{6}$

Time required: allow $3.5 \mathrm{~h}$.

1) Prepare a clean dry $10 \mathrm{~mL}$ round bottomed flask and equip with septum and nitrogen balloon.

2) To the reaction flask, add monomer $4(66.4 \mathrm{mg}, 0.114 \mathrm{mmol}, 6$ equiv. relative to resin loading) followed by $1.7 \mathrm{~mL}$ anhydrous $\mathrm{CH}_{2} \mathrm{Cl}_{2}$ via dry syringe through the septum. Note that full dissolution is not required for eaction success. For the cases where solubility is low, sonication is required to obtain a homogenous slurry before starting next step.

3) While stirring, add 1-chloro-N, N, 2-trimethyl-1-propenylamine (30.2 $\mu \mathrm{L}, 0.228 \mathrm{mmol}$, 12 equiv. relative to resin loading) via dry microsyringe through the septum. Stir for $1 \mathrm{~h}$ at room temperature, under $\mathrm{N}_{2}$.

4) Fit flask with vacuum adaptor and, while stirring, remove solvent and reagents on a vacuum manifold equipped with liquid $\mathrm{N}_{2}$ cold finger. Once evaporated, leave the product (6) to dry for at least a further $2 \mathrm{~h}$ on the vacuum line.

5) Turn off the vacuum and fill the flask back with nitrogen using the dual manifold of the vacuum line or with a nitrogen-filled balloon. Remove the vacuum adaptor, replace septum and ensure that from this point the product remains under positive nitrogen pressure (or under vacuum) until usage.

Protocol 5: Coupling of N-Fmoc quinoline carboxylic acid chloride (6) to resin bound amine (7)

Note: this procedure can also be used for the loading of Sieber amide resin.

Time required: allow $20-40 \mathrm{~min}$. 
1) On the vacuum station thoroughly rinse the inside surfaces of the reaction vessel and the resin with anhydrous THF (approx $10 \mathrm{~mL}$ ) using a dry syringe, ensuring that no DMF remains. Remove all remaining THF, then remove the vessel from the vacuum station and replace end cap.

2) To the round bottomed flask containing acid chloride 6 (quantity corresponding to 0.114 mmol, 6 equiv.) add $2 \mathrm{~mL}$ anhydrous THF via dry syringe through the septum.

3) Add $0.3 \mathrm{~mL}$ anhydrous THF to the resin using a dry syringe, followed by DIEA (20 $\mu \mathrm{L}$, 0.114 mmol, 6 equiv.) using a micropipette. Note that it is essential that DIEA is added prior to the addition of the acid chloride.

4) Using a dry syringe, remove $1 \mathrm{~mL}$ of the acid chloride solution (i.e. corresponding to $0.057 \mathrm{mmol}, 3$ equiv.) and add to the resin.

5) Insert fibre optic probe into the reaction vessel (ensuring the tip is immersed in the reaction mixture) and then place the vessel into the microwave cavity with the appropriate insert. Treat with microwaves: $50 \mathrm{~W}$, ramp to $50{ }^{\circ} \mathrm{C}$. For acid chlorides with poor THF solubility (e.g. 6) we recommend setting the hold time to $15 \mathrm{~min}$. Otherwise hold time should be set at $5 \mathrm{~min}$.

6) Remove reaction vessel from microwave cavity, remove end cap and remove reagent solution on vacuum station. Using a dry syringe, rinse the inside surfaces of the reaction vessel with anhydrous THF $(5 \mathrm{~mL})$ to remove reagents and ensure all displaced resin is moved down to the resin bed. Remove THF on vacuum station and fit end cap to the vessel.

7) Repeat steps 3) to 5). 
8) Remove reaction vessel from microwave cavity, remove fibre optic probe and end cap, then remove reagent solution on vacuum station. Using a dry syringe, rinse the inside surfaces of the reaction vessel and the resin itself with anhydrous THF (approx $10 \mathrm{~mL}$ ). Then, using DMF, thoroughly rinse the inside surfaces of the reaction vessel (approx 10 $\mathrm{mL} \mathrm{DMF}$ ) and the resin itself (approx $10 \mathrm{~mL} \mathrm{DMF}$ ) to ensure all reagents have been removed.

Protocol 6: Assessment of coupling completion using a modified DESC test

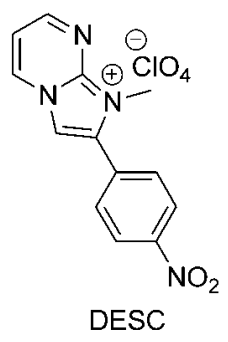

Figure 5: Structure of DESC color test agent.

Note: DESC (Figure 5) should be synthesized using the procedure reported in the literature

(Claerhout, Ermolat'ev \& Van der Eycken, 2008)

Time required: $7 \mathrm{~min}$

1) Remove a very small quantity of resin from the reaction vessel (approximately $20-30$ beads) using a Pasteur pipette or spatula, and place in a small sample vial.

2) Using a Pasteur pipette, add to the sample vial of resin five drops of a $0.1 \mathrm{M}$ solution of DESC in DMF, followed by two drops of a $20 \% \mathrm{v} / \mathrm{v}$ solution of DIEA in DMF.

3) Heat the sample vial at $60{ }^{\circ} \mathrm{C}$ for $5 \mathrm{~min}$.

4) Carefully remove supernatant using a Pasteur pipette, and add fresh DMF. Repeat in this manner until the supernatant is colorless. 
5) Visualise the resin beads under a microscope. Any red-orange coloration indicates that coupling is incomplete (i.e. presence of aromatic amine). The coupling procedure should thus be repeated until no orange coloration is observed with this test.

\section{Protocol 7: Acetylation of the N-terminal aromatic amine}

Time required: $40 \mathrm{~min}$.

1) On the vacuum station thoroughly rinse the inside surface of the reaction vessel and the resin-bound foldamer $\mathbf{8}$ with anhydrous THF (approx $10 \mathrm{~mL}$ ) using a dry syringe, ensuring that no DMF remains. Remove all remaining THF, then remove the vessel from the vacuum station and replace end cap.

2) Using a dry syringe, add $1.3 \mathrm{~mL}$ anhydrous THF to the resin, followed by DIEA (20 $\mu \mathrm{L}$, 0.114 mmol, 6 equiv.) using a micropipette. Then add a diluted acetyl chloride solution $(10 \%, \mathrm{v} / \mathrm{v})$ in anhydrous $\mathrm{THF}(41 \mu \mathrm{L}, 0.057 \mathrm{mmol}, 3$ equiv. $)$ using a dry syringe.

3) Insert fibre optic probe into the reaction vessel (ensuring the tip is immersed in the reaction mixture) and then place the vessel into the microwave cavity with the appropriate insert. Treat with microwaves: $50 \mathrm{~W}$, ramp to $60{ }^{\circ} \mathrm{C}$ with a 15 min hold time.

4) Remove reaction vessel from microwave cavity, remove end cap and remove reagent solution on vacuum station. Using a dry syringe, rinse the inside surfaces of the reaction vessel with anhydrous THF $(5 \mathrm{~mL})$ to remove reagents and ensure all displaced resin is moved down to the resin bed. Remove THF on vacuum station and fit end cap to the vessel.

5) Repeat steps 2) and 3)

6) Remove reaction vessel from microwave cavity, remove fibre optic probe and end cap, then remove reagent solution on vacuum station. Using a dry syringe, rinse the inside 
surfaces of the reaction vessel and the resin itself with anhydrous THF (approx $10 \mathrm{~mL}$ ). Then, using DMF, thoroughly rinse the inside surfaces of the reaction vessel (approx 10 $\mathrm{mL} \mathrm{DMF}$ ) and the resin itself (approx $10 \mathrm{~mL}$ DMF) to ensure all reagents have been removed.

\section{Protocol 8: Cleavage of foldamer from the resin}

Note: this procedure can be used for cleavage of the foldamer from both Wang and Sieber amide resins.

Time required: Drying resin: $15 \mathrm{~h}$; cleavage: $2 \mathrm{~h}$; workup: $2.5 \mathrm{~h}$.

1) Using the vacuum station, rinse the resin sequentially with $\mathrm{DMF}(10 \mathrm{~mL}), \mathrm{CH}_{2} \mathrm{Cl}_{2}(10$ $\mathrm{mL})$ and (1:1) $\mathrm{CH}_{2} \mathrm{Cl}_{2} / \mathrm{MeOH}(10 \mathrm{~mL})$. Use the vacuum station to dry the resin briefly (approx $5 \mathrm{~min}$ ), then transfer the reaction vessel to a desiccator attached to a vacuum manifold and dry the resin under vacuum for approx $15 \mathrm{~h}$.

2) Transfer the resin to a clean, dry $10 \mathrm{~mL}$ round bottomed flask equipped with a magnetic stirring bar.

3) Prepare $1 \mathrm{~mL}$ of TFA/TIS/ $\mathrm{H}_{2} \mathrm{O}(95: 2.5: 2.5 \mathrm{v} / \mathrm{v} / \mathrm{v})$ solution, and add to the resin. Stopper the flask, and stir the mixture for $2 \mathrm{~h}$ at room temperature.

4) Filter the reaction mixture using a clean, dry sintered glass filter funnel and collect the supernatant. Rinse the resin three times with TFA $(3 \times 0.5 \mathrm{~mL})$ and combine the supernatants.

5) Concentrate the TFA solution on a rotary evaporator with a bath temperature of $40^{\circ}$, to obtain a viscous oil. Add diethyl ether to precipitate the product (9), and triturate. Filter the product using a clean, dry sintered glass filter funnel, dry and desiccate (approx $2 \mathrm{~h}$ on a vacuum manifold). 
6) Purify the product using preparative RP-HPLC.

2 7-Amino-8-fluoro-2-quinolinecarboxylic acid-based oligoamides
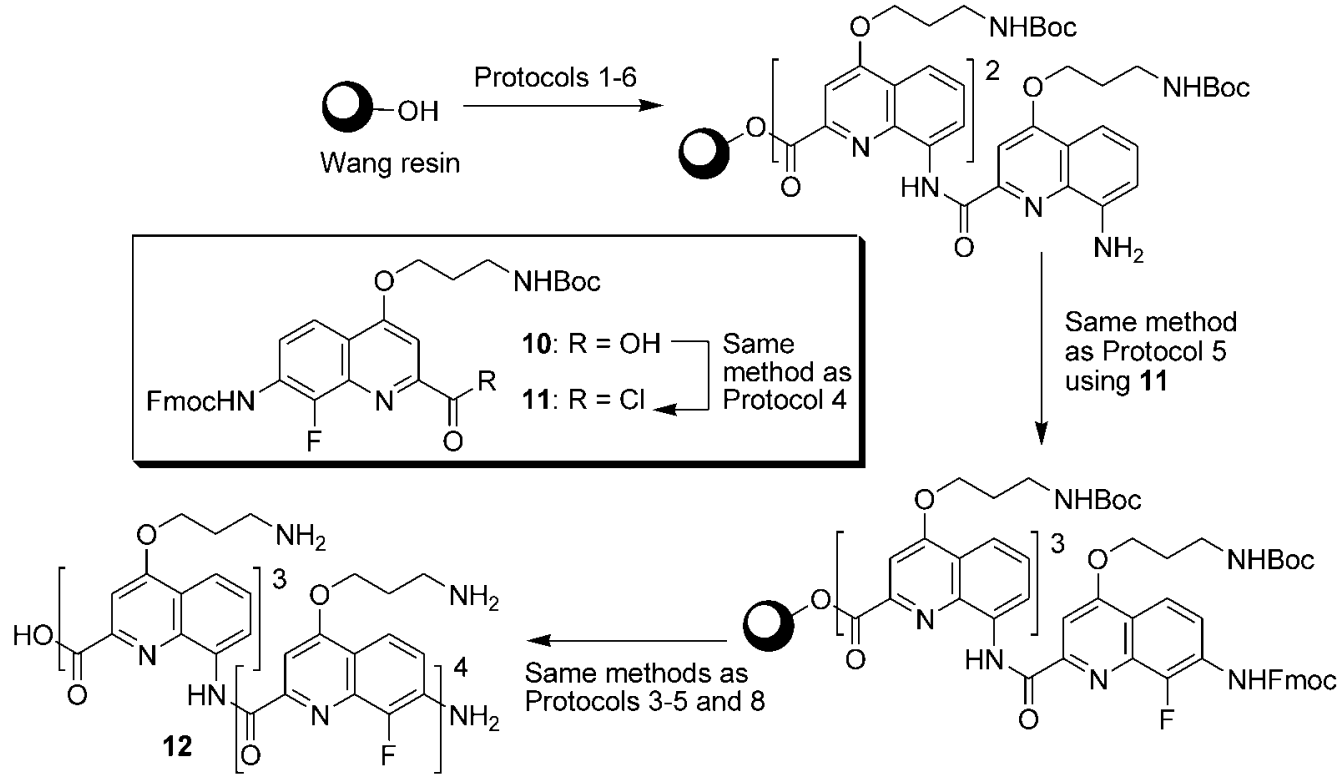

Figure 6: SPS of 7-amino-8-fluoro-2-quinolinecarboxylic acid-based oligoamides exemplified by synthesis of the antiparallel double helix-forming sequence 12 (Shang et al, 2014)

\section{Advice on SPS of 7-amino-8-fluoro-2-quinolinecarboxylic acid-based oligoamides}

Note: SPS of 12 (Figure 6) can be carried out using the same methods as described in protocols for 8-amino-2-quinolinecarboxylic acid-based oligoamides, with the following exceptions and advice:

1) Protocol 6: In contrast with the 8-amino-quinoline, the 7-amino-8-fluoro-quinoline was found to afford a pale yellow coloration using the DESC test, which was difficult to observe. Therefore we advise that coupling completion should be confirmed by cleaving a small aliquot of resin and analyzing the resulting product(s) via ${ }^{1} \mathrm{H}-\mathrm{NMR}$ and LC-MS. 
2) Protocol 8: The fluoroquinoline amine was found to be particularly susceptible to trifluoroacetylation when undergoing cleavage from the resin (Shang et al, 2014). We therefore advise that if possible, this functionality is blocked (via acylation or otherwise) during this step.

3) Purification/characterization: It should be noted that products from SPS of these sequences are potentially capable of self- and cross-hybridization (both parallel and antiparallel) after cleavage from the resin. Therefore to avoid difficulties in purification it is recommended that:

(a) Each coupling step should be verified as complete in order to avoid as much as possible the presence of deletion sequences (see also point 1).

(b) Where possible, the sequence should be designed with a quinoline trimer motif at one terminus which codes for a single helical segment. Since this has no propensity to self-associate, it will force exclusively anti-parallel duplex formation.

Final purification should be carried out by RP-HPLC as for the 8-amino-2quinolinecarboxylic acid-based oligoamides.

\section{$3 \quad$ Quinoline/ $\alpha$-amino acid hybrid oligoamides}




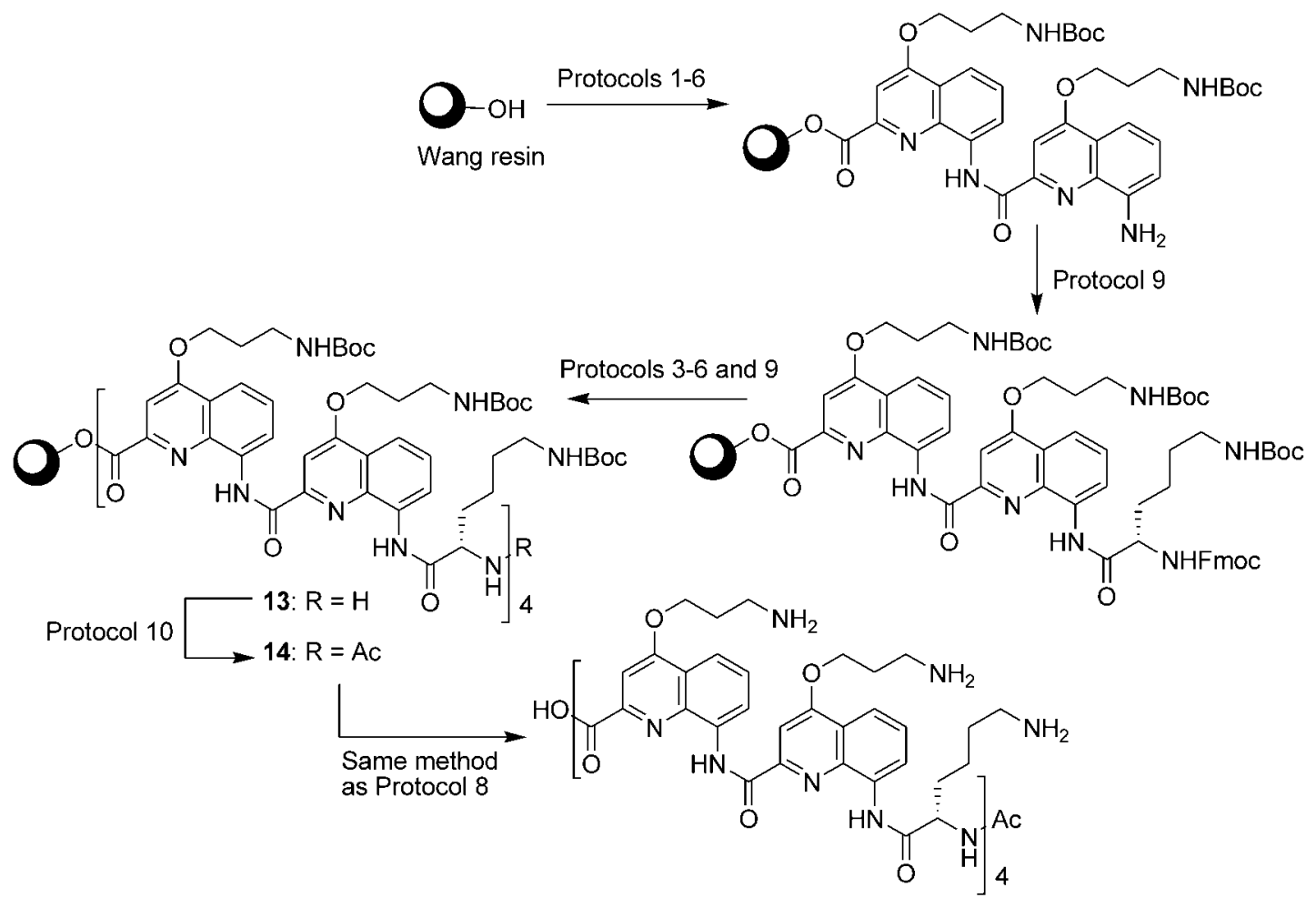

Figure 7: SPS of quinoline/ $\alpha$-amino acid hybrid oligoamides exemplified by the $\mathrm{XQ}_{2}$-based sequence $\mathrm{Ac}-\left(\mathrm{KQ}^{\mathrm{Orn}}{ }_{2}\right)_{4}-\mathrm{OH}$

Note: Methods described in Protocols $1-8$ can be used unchanged for the synthesis of quinoline/ $\alpha$-amino acid hybrid oligoamides (Figure 7). Coupling of quinoline monomers to the $\alpha$-amino acid aliphatic amine can be carried out using Protocols 4 and 5 even though other activation methods work as well. Note that for these sequences, all protocols have only been currently validated using Wang resin. They are also not suitable for use with cysteine or 2aminoisobutyric acid, due to racemization and poor reactivity, respectively.

Protocol 9: Coupling of $\alpha$-amino acid to the quinoline amine via in situ acid chloride formation Time required: $40 \mathrm{~min}$. 
1) On the vacuum station thoroughly rinse the inside surfaces of the reaction vessel and the resin with anhydrous THF (approx $10 \mathrm{~mL}$ ) using a dry syringe, ensuring that no DMF remains. Remove remaining $\mathrm{THF}$, then remove the vessel from the vacuum station and replace end cap.

2) Add $0.3 \mathrm{~mL}$ anhydrous THF to the resin using a dry syringe, followed by $2,4,6$-collidine (21.8 $\mu \mathrm{L}, 0.165 \mathrm{mmol}, 8.7$ equiv.) using a micropipette.

3) Prepare a clean dry $10 \mathrm{~mL}$ round bottomed flask and equip with septum and nitrogen balloon.

4) To the flask, add Fmoc-Lys(Boc)-OH (17.8 mg, $0.038 \mathrm{mmol}, 2$ equiv. relative to resin loading) and $\mathrm{PPh}_{3}(54.8 \mathrm{mg}, 0.21 \mathrm{mmol}, 11$ equiv.) followed by $1 \mathrm{~mL}$ anhydrous THF via syringe through the septum. While stirring, add TCAN (16.5 $\mu \mathrm{L}, 0.165 \mathrm{mmol}, 8.7$ equiv.) via dry microsyringe through the septum. Using a dry syringe, immediately transfer the resulting mixture to the resin.

5) Insert optical fibre probe into the reaction vessel (ensuring the tip is immersed in the reaction mixture) and then place the vessel into the microwave cavity with the appropriate insert. Treat with microwaves: $50 \mathrm{~W}$, ramp to $50{ }^{\circ} \mathrm{C}$ with a 15 min hold time.

6) Remove reaction vessel from microwave cavity, remove end cap and remove reagent solution on vacuum station. Using DMF, thoroughly rinse the inside surfaces of the reaction vessel (approx $10 \mathrm{~mL}$ DMF) and the resin itself (approx $10 \mathrm{~mL}$ DMF) to ensure all reagents have been removed. Then, using a dry syringe, rinse the inside surfaces of the reaction vessel and the resin itself again with anhydrous THF (approx $10 \mathrm{~mL}$ ) to remove the remaining DMF. Remove THF on vacuum station and fit end cap to the vessel. 
7) Repeat steps 2) to 6). Note: the number of repeat cycles may depend on the Fmoc $\alpha$ amino acid used. Coupling completion can be determined using Protocol 6. For further details, see Hu et al, 2016.

8) Remove reaction vessel from microwave cavity, remove fibre optic probe and end cap, then remove reagent solution on vacuum station. Using DMF, thoroughly rinse the inside surfaces of the reaction vessel (approx $10 \mathrm{~mL} \mathrm{DMF}$ ) and the resin itself (approx $10 \mathrm{~mL}$ DMF) to ensure all reagents have been removed.

Protocol 10: Acetylation of aliphatic N-terminal amine

On the vacuum station thoroughly Time required: $50 \mathrm{~min}$.

1) Rinse the inside surface of the reaction vessel and the resin with anhydrous DMF (approx $10 \mathrm{~mL}$ ) using a dry syringe. Remove residual anhydrous DMF from the reaction vessel using the vacuum station. Then remove the vessel from the vacuum station and replace end cap.

2) Using a dry syringe, add $1.3 \mathrm{~mL}$ anhydrous DMF to the resin, followed by DIEA (66.7 $\mu \mathrm{L}, 0.38 \mathrm{mmol}, 20$ equiv.) using a micropipette. Then add acetic anhydride $(17.9 \mu \mathrm{L}$, 0.19 mmol, 10 equiv.) using a micropipette.

3) Insert optical fibre probe into the reaction vessel (ensuring the tip is immersed in the reaction mixture) and then place the vessel into the microwave cavity with the appropriate insert. Treat with microwaves: $25 \mathrm{~W}$, ramp to $25^{\circ} \mathrm{C}$ with a 20 min hold time.

4) Remove reaction vessel from microwave cavity, remove end cap and remove reagent solution on vacuum station. Using a dry syringe, rinse the inside surfaces of the reaction vessel with anhydrous DMF $(5 \mathrm{~mL})$ to remove reagents and ensure all displaced resin is 
moved down to the resin bed. Remove residual anhydrous DMF on vacuum station and fit end cap to the vessel.

5) Repeat steps 2) and 3)

6) Remove reaction vessel from microwave cavity, remove fibre optic probe and end cap, then remove reagent solution on vacuum station. Using DMF, thoroughly rinse the inside surfaces of the reaction vessel (approx $10 \mathrm{~mL} \mathrm{DMF)} \mathrm{and} \mathrm{the} \mathrm{resin} \mathrm{itself} \mathrm{(approx} 10 \mathrm{~mL}$ DMF) to ensure all reagents have been removed.

\section{Characterization of foldamers}

The following section shows analytical RP-HPLC and ${ }^{1} \mathrm{H}$ NMR characterization of examples of 8-amino-2-quinolinecarboxylic acid-based oligoamides, 7-amino-8-fluoro-2-quinolinecarboxylic acid-based oligoamides and quinoline/ $\alpha$-amino acid hybrid oligoamides. Analytical RP-HPLC

was carried out on a Macherey-Nagel Nucleodur $\mathrm{C}_{18}$ gravity column $(4.6 \times 100 \mathrm{~mm}, 3 \mu \mathrm{m})$ at 1.5 $\mathrm{mL} / \mathrm{min}$, running solvents: MilliQ water containing $0.1 \%$ v/v TFA (solvent $\mathrm{A}$ ), $\mathrm{CH}_{3} \mathrm{CN}$ containing $0.1 \%$ v/v TFA (solvent B). Gradients were as follows: 20 - 28\% B over 10 min (System A); 5 - 100\% B over 15 min (System B); 13 - 18\% B over 10 min (System C).

\section{8-Amino-2-quinolinecarboxylic acid-based oligoamides}

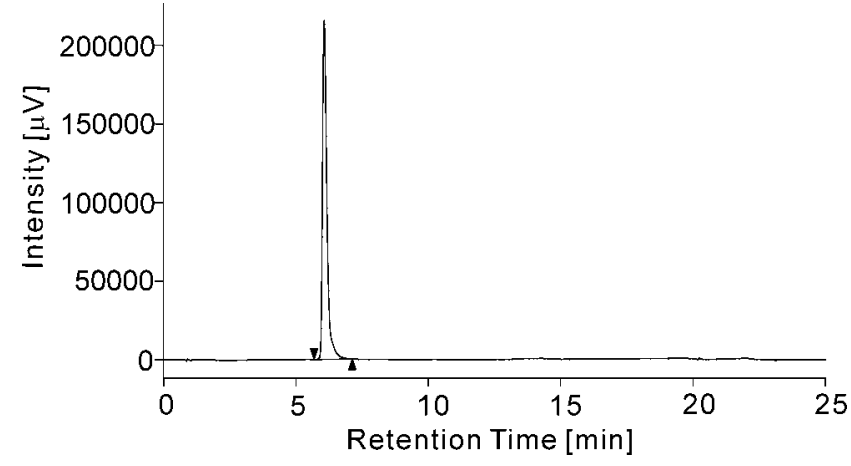

Figure 8: Analytical RP-HPLC chromatogram (System A) of the 12mer Ac$\left(\mathrm{Q}^{\mathrm{Asp}}\left(\mathrm{Q}^{\mathrm{Orn}}\right)_{2} \mathrm{Q}^{\mathrm{Ala}} \mathrm{Q}^{\mathrm{Orn}}\right)_{2} \mathrm{Q}^{\mathrm{Asp}} \mathrm{Q}^{\mathrm{Orn}}-\mathrm{OH}$ after purification by preparative RP-HPLC. 


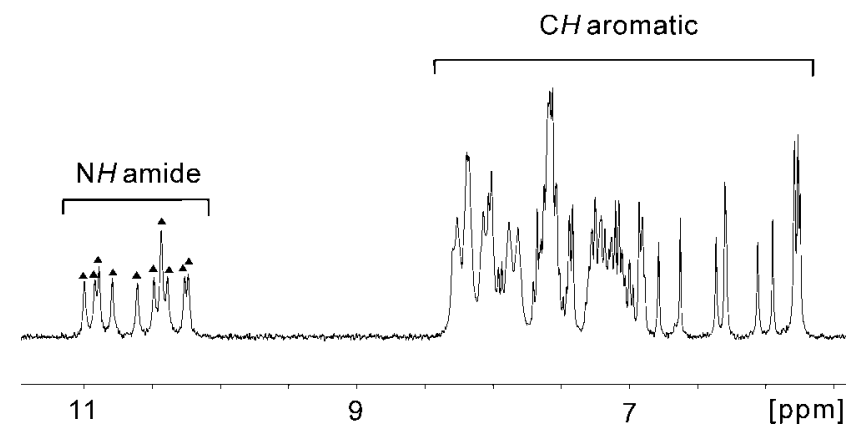

Figure 9: Excerpt of the ${ }^{1} \mathrm{H}$ NMR spectrum $(300 \mathrm{MHz})$ at $298 \mathrm{~K}$ of Ac$\left(\mathrm{Q}^{\mathrm{Asp}}\left(\mathrm{Q}^{\mathrm{Orn}}\right)_{2} \mathrm{Q}^{\mathrm{Ala}} \mathrm{Q}^{\mathrm{Orn}}\right)_{2} \mathrm{Q}^{\mathrm{Asp}} \mathrm{Q}^{\mathrm{Orn}}-\mathrm{OH}$ in DMSO-d . Solid triangles indicate the eleven amide $\mathrm{NH}$ signals of the $12 \mathrm{mer}$.

2 7-Amino-8-fluoro-2-quinolinecarboxylic acid-based oligoamides

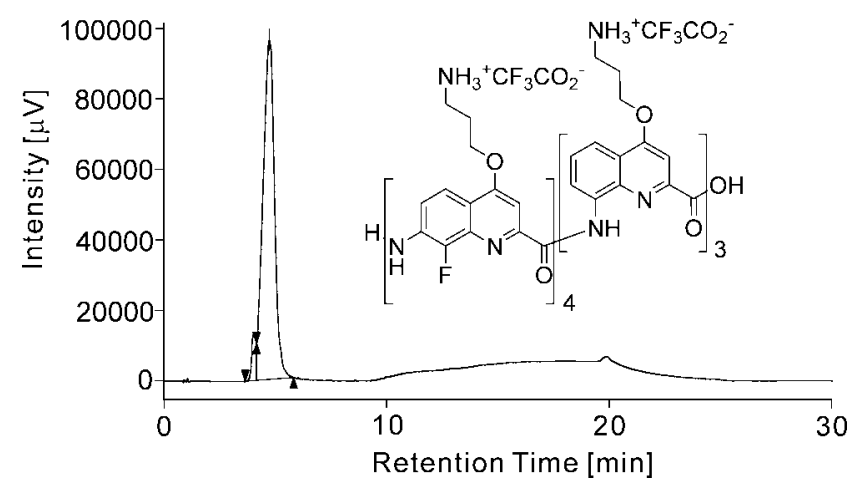

Figure 10: Analytical RP-HPLC chromatogram (System B) of the $7 \mathrm{mer}\left(\mathrm{Q}_{\mathrm{F}}{ }^{\mathrm{Orn}}\right)_{4}\left(\mathrm{Q}^{\mathrm{Orn}}\right)_{3}-\mathrm{OH}$ (structure shown in insert) after purification by preparative RP-HPLC.

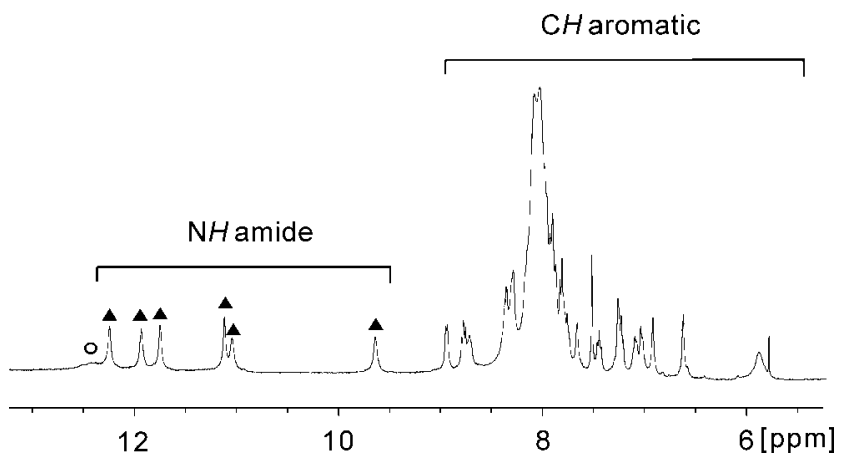




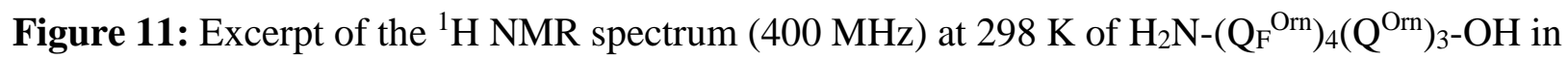
DMSO- $\mathrm{d}_{6}$. Solid triangles and the blank circle indicate the 6 amide signals and the carboxylic acid signal of the $7 \mathrm{mer}$, respectively. Note in this solvent, the oligomer is in single helical form (Shang et al, 2014).

3 Quinoline/ $\alpha$-amino acid hybrid oligoamides

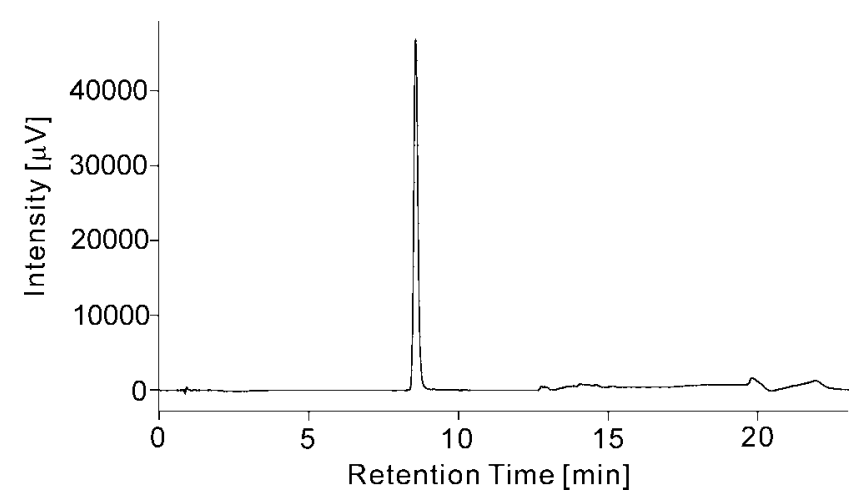

Figure 12: Analytical RP-HPLC chromatogram (System C) of Ac$\mathrm{K}\left(\mathrm{Q}^{\mathrm{Orn}}\right)_{2} \mathrm{~A}\left(\mathrm{Q}^{\mathrm{Orn}}\right)_{2} \mathrm{D}\left(\mathrm{Q}^{\mathrm{Orn}}\right)_{2} \mathrm{~S}\left(\mathrm{Q}^{\mathrm{Orn}}\right)_{2}-\mathrm{OH}$ after purification by preparative $\mathrm{RP}-\mathrm{HPLC}$.

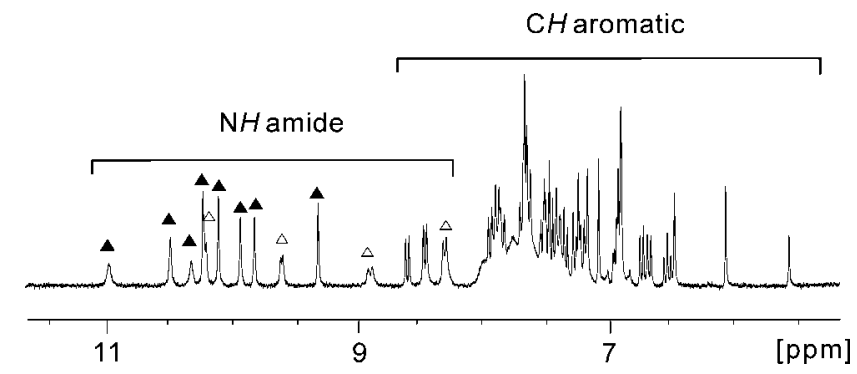

Figure 13: Excerpt of the ${ }^{1} \mathrm{H}$ NMR spectrum (800 MHz) at $298 \mathrm{~K}$ of Ac$\mathrm{K}\left(\mathrm{Q}^{\mathrm{Orn}}\right)_{2} \mathrm{~A}\left(\mathrm{Q}^{\mathrm{Orn}}\right)_{2} \mathrm{D}\left(\mathrm{Q}^{\mathrm{Orn}}\right)_{2} \mathrm{~S}\left(\mathrm{Q}^{\mathrm{Orn}}\right)_{2}-\mathrm{OH}$ in $\mathrm{D}_{2} \mathrm{O} / \mathrm{H}_{2} \mathrm{O}$ (1:9). Solid and hollow triangles indicate amide signals from eight aromatic and four aliphatic amines of the $12 \mathrm{mer}$, respectively.

\section{References}


Appella, D. H., Christianson, L. A., Karle, I. L., Powell, D. R., Gellman. S. H. (1996). $\beta$-Peptide foldamers: robust helix formation in a new family of $\beta$-amino acid oligomers. J. Am. Chem. Soc. $118,13071-13072$.

Bao, C., Kauffmann, B., Gan, Q., Srinivas, K., Jiang, H., Huc, I. (2008). Converting sequences of aromatic amino acid monomers into functional three-dimensional structures: secondgeneration helical capsules. Angew. Chem., Int. Ed. 47, 4153 - 4156.

Barnard, A., Long, K., Martin, H. L., Miles, J. A., Edwards, T. A., Tomlinson, D. C., Macdonald, A., Wilson, A. J. (2015). Selective and potent proteomimetic inhibitors of intracellular protein-protein interactions. Angew. Chem. Int. Ed. 54, 2960 - 2965. Baptiste, B., Douat-Casassus, C., Laxmi-Reddy, K., Godde, F., Huc, I. (2010). Solid phase synthesis of aromatic oligoamides: application to helical water-soluble foldamers. J. Org. Chem. $75,7175-7185$.

Bassani, D. M., Lehn, J.-M., Baum, G., Fenske, D. (1997). Designed self-generation of an extended helical structure from an achiral polyheterocylic strand. Angew. Chem. Int. Ed. Engl. $36,1845-1847$.

Berl, V., Huc, I., Khoury, R., Krische, M., Lehn, J.-M. (2000). Interconversion of single and double helices formed from synthetic molecular strands. Nature 407, 720 - 723.

Buratto, J., Colombo, C., Stupfel, M., Dawson, S. J., Dolain, C., Langlois d'Estaintot, B., Fischer, L., Granier, T., Laguerre, M., Gallois, B., Huc, I. (2014). Structure of a complex formed by a protein and a helical aromatic oligoamide foldamer at $2.1 \AA$ A resolution. Angew. Chem. Int. Ed. 53, $883-887$. 
Chandramouli, N., Ferrand, Y., Lautrette, G., Kauffmann, B., Mackereth, C. D., Laguerre, M., Dubreuil, D., Huc, I. (2015). Iterative design of a helically folded aromatic oligoamide sequence for the selective encapsulation of fructose. Nat. Chem. 7, $334-341$.

Claerhout, S., Ermolat'ev, D. S., Van der Eycken, E. V. (2008). A new colorimetric test for solid-phase amines and thiols. J. Comb. Chem. 10, $580-585$.

Delaurière, L., Dong, Z., Laxmi-Reddy, K., Godde, F., Toulmé, J.-J., I. Huc. (2012).

Deciphering aromatic oligoamide foldamer-DNA interactions. Angew. Chem. Int. Ed. 51, 473 477.

Dolain, C., Grélard, A., Laguerre, M., Jiang, H., Maurizot, V., Huc, I. (2005). Solution structure of quinoline- and pyridine-derived oligoamide foldamers. Chem. Eur. J. 11, 6135.

Ferrand, Y., Chandramouli, N., Kendhale, A. M., Aube, C., Kauffmann, B., Grélard, A., Laguerre, M., Dubreuil, D., Huc, I. (2012). Long-range effects on the capture and release of a chiral guest by a helical molecular capsule. J. Am. Chem. Soc. 134, $11282-11288$.

Gan, Q., Bao, C., Kauffmann, B., Grélard, A., Xiang, J., Liu, S., Huc, I., Jiang, H. (2008). Quadruple and double helices of 8-fluoroquinoline oligoamides. Angew. Chem. Int. Ed. 47, 1715 $-1718$.

Garric, J., Léger, J.-M., Huc, I. (2005). Molecular apple peels. Angew. Chem. Int. Ed. 44, 1954 1958.

Gillies, E., Deiss, F., Staedel, C., Schmitter, J.-M. Huc, I. (2007). Development and biological assessment of fully water-soluble helical aromatic amide foldamers. Angew. Chem. Int. Ed. 46, $4081-4084$.

Guichard, G., Huc, I. (2011). Synthetic foldamers. Chem. Commun. 47, 5933 - 5941. 
Hamuro, Y., Geib, S. J., Hamilton, A. D. (1996). Oligoanthranilamides. Non-peptide subunits that show formation of specific secondary structure. J. Am. Chem. Soc. 118, $7529-7541$. Hu, X., Dawson, S. J., Kudo, M., Nagaoka, Y., Tanatani, A., Huc, I. (2016). Solid-phase synthesis of water-soluble helically folded hybrid $\alpha$-amino acid/quinoline oligoamides. J. Org. Chem. 81, $1137-1150$.

Huc, I. (2004). Aromatic oligoamide foldamers. Eur. J. Org. Chem. 17 - 29. Iriondo-Alberdi, J., Laxmi-Reddy, K., Bouguerne, B., Staedel, C., Huc, I. (2010). Cellular internalization of water-soluble helical aromatic amide foldamers. ChemBioChem 11, 1679 1685.

Jiang, H., Léger, J.-M. Huc, I. (2003). Aromatic delta-peptides. J. Am. Chem. Soc. 125, 3448 3449.

Jiang, H., Léger, J.-M., Dolain, C., Guionneau, P., Huc, I. (2003). Aromatic delta-peptides: design, synthesis, and structural studies of helical, quinoline-derived oligoamide foldamers. Tetrahedron 59, 8365

König, H. M., Abbel, R., Schollmeyer, D., Kilbinger, A. F. (2006). Solid-phase synthesis of oligo(p-benzamide) foldamers. Org. Lett. 8, 1819 - 1822.

Kudo, M., Maurizot, V., Kauffmann, B., Tanatani, A., Huc, I. (2013). Folding of a linear array of a-amino acids within a helical aromatic oligoamide frame. J. Am. Chem. Soc. 135, 9628 - 9631. Kudo, M., Maurizot, V., Masu, H., Tanatani, A., Huc, I. (2014). Structural elucidation of foldamers with no long range conformational order. Chem. Commun. 50, 10090 - 10093. Li, X., Yang, D. (2006). Peptides of aminoxy acids as foldamers. Chem. Commun. 2006, 3367 3379. 
Lokey, R. S., Iverson, B. L. (1995). Synthetic molecules that fold into a pleated secondary structure in solution. Nature 375, $303-305$.

Morales, G. A., Corbett, J. W., DeGrado, W. F. (1998). Solid-phase synthesis of benzopiperazinones. J. Org. Chem. 63, $1172-1177$.

Müller, S., Laxmi-Reddy, K., Jena, P. V., Baptiste, B., Dong, Z., Godde, F., Ha, T., Rodriguez, R., Balasubramanian, S., Huc, I. (2014). Targeting DNA G-quadruplexes with helical small molecules. ChemBioChem 15, 2563 - 2570.

Murphy, N. S., Prabhakaran, P., Azzarito, V., Plante, J. P., Hardie, M. J., Kilner, C. A., Warriner, S. L., Wilson, A. J. (2013). Solid-phase methodology for synthesis of O-alkylated aromatic oligoamide inhibitors of $\alpha$-helix-mediated protein-protein interactions. Chem. Eur. J. 19, 5546 5550.

Nair, R. V., Vijayadas, K. N., Roy, A., Sanjayan, G. J. (2014). Heterogeneous foldamers from aliphatic-aromatic amino acid building blocks: current trends and future prospects. Eur. J. Org. Chem. 7763-7780.

Nelson, J. C., Saven, J. G., Moore, J. S., Wolynes, P. G. (1997). Solvophobically driven folding of nonbiological oligomers. Science, 277, 1793 - 1796.

Nielsen, P. E., Egholm, M., Berg, R. H., Buchardt, O. (1991). Sequence-selective recognition of DNA by strand displacement with a thymine-substituted polyamide. Science, 254, 1497 - 1500.

Puckett, J. W., Green, J. T., Dervan, P. B. (2012). Microwave assisted synthesis of Py-Im polyamides. Org. Lett. 14, $2774-2777$.

Qi, T., Maurizot, V., Noguchi, H., Charoenraks, T., Kauffmann, B., Takafuji, M., Ihara, H., Huc, I. (2012). Solvent dependence of helix stability in aromatic oligoamide foldamers. Chem. Commun. 48, $6337-6339$. 
Salaun, A., Potel, M., Roisnel, T., Gall, P., Le Grel, P. (2005). Crystal structures of aza-beta3peptides, a new class of foldamers relying on a framework of hydrazinoturns. J. Org. Chem. 70, $6499-6502$.

Seebach, D., Overhand, M., Kühnle, F. N.M., Martinoni, B., Oberer, L., Hommel, U., Widmer, H. (1996). $\beta$-Peptides: Synthesis by Arndt-Eistert homologation with concomitant peptide coupling. Structure determination by NMR and CD spectroscopy and by X-ray crystallography. Helical secondary structure of a $\beta$-hexapeptide in solution and its stability towards pepsin. Helv. Chim. Acta, 79, $913-941$.

Semetey, V., Rognan, D., Hemmerlin, C., Graff, R., Briand, J.-P., Marraud, M., Guichard, G. (2002). Stable helical secondary structure in short-chain N,N'-linked oligoureas bearing proteinogenic side chains. Angew. Chem. Int. Ed. 41, 1893 - 1895.

Shang, J., Gan, Q., Dawson, S. J., Rosu, F., Jiang, H., Ferrand, Y., Huc, I. (2014). Selfassociation of aromatic oligoamide foldamers into double helices in water. Org. Lett. 16, $4992-$ 4995.

Shi, R., Wang, F., Yan, B. (2007). Site-Site Isolation and Site-Site Interaction - Two Sides of the Same Coin. Int. J. Pept. Res. Ther. 13, 213 - 219.

Simon, R. J., Kania, R. S., Zuckermann, R. N., Huebner, V. D., Jewell, D. A., Banville, S., Ng, S., Wang, L., Rosenberg, S., Marlowe, C. K., Spellmeyer, D.C., Tan, R., Frankel, A.D. Santi, D.V., Cohen, F. E., Bartlett, P. A. (1992). Peptoids: a modular approach to drug discovery. Proc. Natl. Acad. Sci. U. S. A. 89, 9367 - 9371.

Singleton, M. L., Pirotte, G., Kauffmann, B., Ferrand, Y., Huc, I. (2014). Increasing the size of an aromatic helical foldamer cavity by strand intercalation. Angew. Chem. Int. Ed. 53, 13140 13144. 
White, P. D. \& Chan, W. C. (2000). Basic Procedures. In White, P. D. \& Chan, W. C. Fmoc Solid Phase Synthesis: A Practical Approach. (p. 44). Oxford: Oxford University Press.

Wurtz, N. R., Turner, J. M., Baird, E. E., Dervan, P. B. (2001). Fmoc solid phase synthesis of polyamides containing pyrrole and imidazole amino acids. Org. Lett. 3, $1201-1203$.

Zhu, J., Parra, R. D., Zeng, H., Skrzypczac-Jankun, E., Zeng, X. C., Gong, B. (2000). A new class of folding oligomers: crescent oligoamides. J. Am. Chem. Soc. 122, $4219-4220$. 